\title{
Methylation of the 3p22 region encompassing $M L H 1$ is representative of the CpG island methylator phenotype in colorectal cancer
}

\author{
Justin J-L Wong ${ }^{1}$, Nicholas J Hawkins ${ }^{1,3}$, Robyn L Ward ${ }^{2,3}$ and Megan P Hitchins ${ }^{2,3}$ \\ ${ }^{1}$ School of Medical Sciences, University of New South Wales, Sydney, NSW, Australia; ${ }^{2}$ Adult Cancer \\ Program, Lowy Cancer Research Centre, University of New South Wales, Sydney, NSW, Australia and \\ ${ }^{3}$ Prince of Wales Clinical School, University of New South Wales, Sydney, NSW, Australia
}

\begin{abstract}
Epigenetic silencing of cancer-related genes by promoter methylation is a frequent event in sporadic colorectal cancer. The CpG island methylator phenotype (CIMP + ), in which discrete genes throughout the genome are simultaneously methylated, and long-range epigenetic silencing, whereby multiple genes within contiguous chromosomal regions are methylated, have been described in subsets of colorectal cancer. We previously reported the concurrent methylation of the mismatch repair gene MLH1 with a cluster of flanking genes in chromosome region 3p22 in sporadic colorectal carcinoma exhibiting microsatellite instability and the BRAF V600E mutation. Herein, we aimed to determine whether methylation of MLH1 and neighbouring 3p22 genes, singly or concomitantly, correlate with the germline c.-93G $>$ A SNP within the MLH1 promoter, CIMP + and other clinicopathological and molecular features of the tumours. By studying a cohort of 946 sporadic colorectal cancer cases, we show a strong association between concordant methylation of $\geq 3$ of five 3p22 genes with CIMP + and the BRAF V600E mutation $(P<0.001)$. These associations were independent of microsatellite instability, as concomitant methylation of 3p22 genes other than MLH1 was found in microsatellite stable cancers. These findings show that long-range epigenetic silencing across 3p22 occurs in the context of CIMP + and the BRAF V600E mutation, and only gives rise to microsatellite instability when this process encompasses MLH1. Furthermore, the strong relationship between long-range epigenetic silencing of 3p22 and CIMP + provides further evidence that these two purportedly distinct epigenetic phenotypes represent a single entity with a common aetiology. Low-level methylation of $M L H 1$ and flanking 3 p22 genes, as well as the BRAF V600E mutation, were detected in the apparently normal colonic mucosa of a small number of cases whose tumours showed a similar molecular profile, suggesting that these concurring genetic and epigenetic events can occur as a field defect in neoplastic development.

Modern Pathology (2011) 24, 396-411; doi:10.1038/modpathol.2010.212; published online 19 November 2010
\end{abstract}

Keywords: CIMP; colorectal cancer; long-range epigenetic silencing; methylation; $M L H 1$

Epigenetic silencing of various tumour-suppressor and DNA repair genes by cytosine methylation of promoter-associated $\mathrm{CpG}$ islands is a frequent event in sporadic colorectal cancer. ${ }^{1}$ A classic example of this is the biallelic promoter methylation of the mismatch repair gene, MLH1, which accounts for $\sim 70 \%$ of sporadic colorectal cancers that exhibit microsatellite instability as a direct consequence of

Correspondence: Dr MP Hitchins, PhD, Medical Epigenetics Laboratory, Adult Cancer Program, Lowy Cancer Research Centre, University of New South Wales, Sydney, NSW 2052, Australia. E-mail: m.hitchins@unsw.edu.au

Received 13 July 2010; revised 14 September 2010; accepted 14 September 2010; published online 19 November 2010 impaired mismatch repair activity. ${ }^{2-5}$ MLH1 methylation occurs in close association with the presence of the oncogenic BRAF V600E mutation in sporadic colorectal cancer. ${ }^{6}$ The c.-93G > A SNP (rs1800734) within the MLH1 promoter has been associated with an increased risk of microsatellite instability or MLH1 methylation in some colorectal and endometrial cancer populations, but not in others. ${ }^{7-10}$ However, these associations have been disputed on the basis that linkage disequilibrium with pathogenic mutations could not be ruled out in populations with a high incidence of familial cancer. ${ }^{11}$ Recently, promoter reporter assays showed that the A allele of this SNP conferred reduced transcriptional activity compared with the G allele, 
consistent with the notion that this allele might predispose to promoter methylation. ${ }^{12}$ The potential role for genetic-based variants in conferring susceptibility of MLH1 to epigenetic silencing thus remains in question.

In recent years, there has been increasing evidence that aberrant methylation in sporadic colorectal cancer tends to occur in consistent patterns, which are associated with particular clinicopathological and molecular features. The $\mathrm{CpG}$ island methylator phenotype (CIMP) has been proposed to describe the simultaneous methylation of multiple but discrete $\mathrm{CpG}$ islands at distinct loci throughout the genome in the development of a subset of colorectal cancers, now referred to as CIMP.$+{ }^{13-15}$ Interestingly, the CIMP + phenotype also correlates closely with the presence of the BRAF V600E mutation, MLH1 methylation and microsatellite instability, ${ }^{13-16}$ although the basis for the inter-relationship between these genetic and epigenetic phenomena remains unknown. More recently, long-range epigenetic silencing, in which concordant $\mathrm{CpG}$ island methylation and chromatin modification across large genomic regions induces silencing of multiple contiguous genes, has also been demonstrated for specific chromosomal regions in a proportion of sporadic colorectal cancers. ${ }^{17,18}$ Long-range epigenetic silencing was initially demonstrated for chromosome region 2q14.2, exerting an effect equivalent to an acquired genetic deletion of this large chromosomal region. ${ }^{17}$ In a previous study by our group, we demonstrated that methylation of MLH1 in sporadic microsatellite unstable colorectal cancer is also not typically confined to this gene. ${ }^{18}$ Consistent with long-range

Figure 1 Chromosome region 3p22 and close association between methylation of genes within this region and CIMP + and BRAF V600E mutation in sporadic colorectal cancer. (a) Map of the 3p22 region encompassing MLH1. Genes are represented as boxes, with black boxes showing genes frequently methylated in colorectal cancer and white boxes for genes unmethylated in colorectal cancer. Genes transcribed from the sense strand are located above the horizontal line and gene transcribed from the antisense strand are beneath it. Horizontal arrows indicate transcriptional direction. Numbers indicate the distance with respect to MLH1 in kilobases. (b, left) Dendrogram and heat map generated by hierarchical clustering analysis of five 3 p22 genes, illustrating the strong association between methylation of this cluster in sporadic colorectal cancer. Each horizontal line in the heat map represents a single colorectal cancer sample. Black and grey represent the presence and absence of methylation, respectively. The 1-similarity scale represents the distance metric ranged from 0 to 1 , providing a measure of the strength of association between concomitant methylation at each gene with respect to MLH1 (the smaller the 1-similarity value, the stronger the association). (b, right) Heat map showing BRAF V600 mutation, microsatellite and CIMP status, with tumours aligned alongside the heat map of 3 p22 methylation status, but were not included in the cluster analysis. BRAF V600E mutant, microsatellite instability (MSI) and CIMP + samples are in black, BRAF wild type, microsatellite stability (MSS) and CIMP- are in grey. Missing data points are in white. Colorectal cancers that are CIMP + and BRAF mutant are predominantly methylated at $\geq 13 \mathrm{p} 22$ genes, and 96 of microsatellite unstable tumours are methylated at MLH1. epigenetic silencing, we found that MLH1 and flanking genes AB002340, ITGA9, PLCD1 and DLEC1 spanning a 1.1-Mb region of chromosome 3p22 were differentially methylated and transcriptionally inactivated in sporadic microsatellite unstable cancers, but not in microsatellite stable cancers. The methylated 3p22 genes were interspersed with other genes that escaped CpG methylation, but were nevertheless also downregulated (summarized in Figure 1a). ${ }^{18}$ This regional pattern of dense 3p22 methylation was cancer specific, as it was not found in the paired normal colorectal mucosa of the colorectal cancer cases using combined bisulphite restriction analysis. Several of these 3p22 genes, including ITGA9, PLCD1 and the putative tumour-suppressor gene DLEC1, are commonly inactivated through methylation or deletion
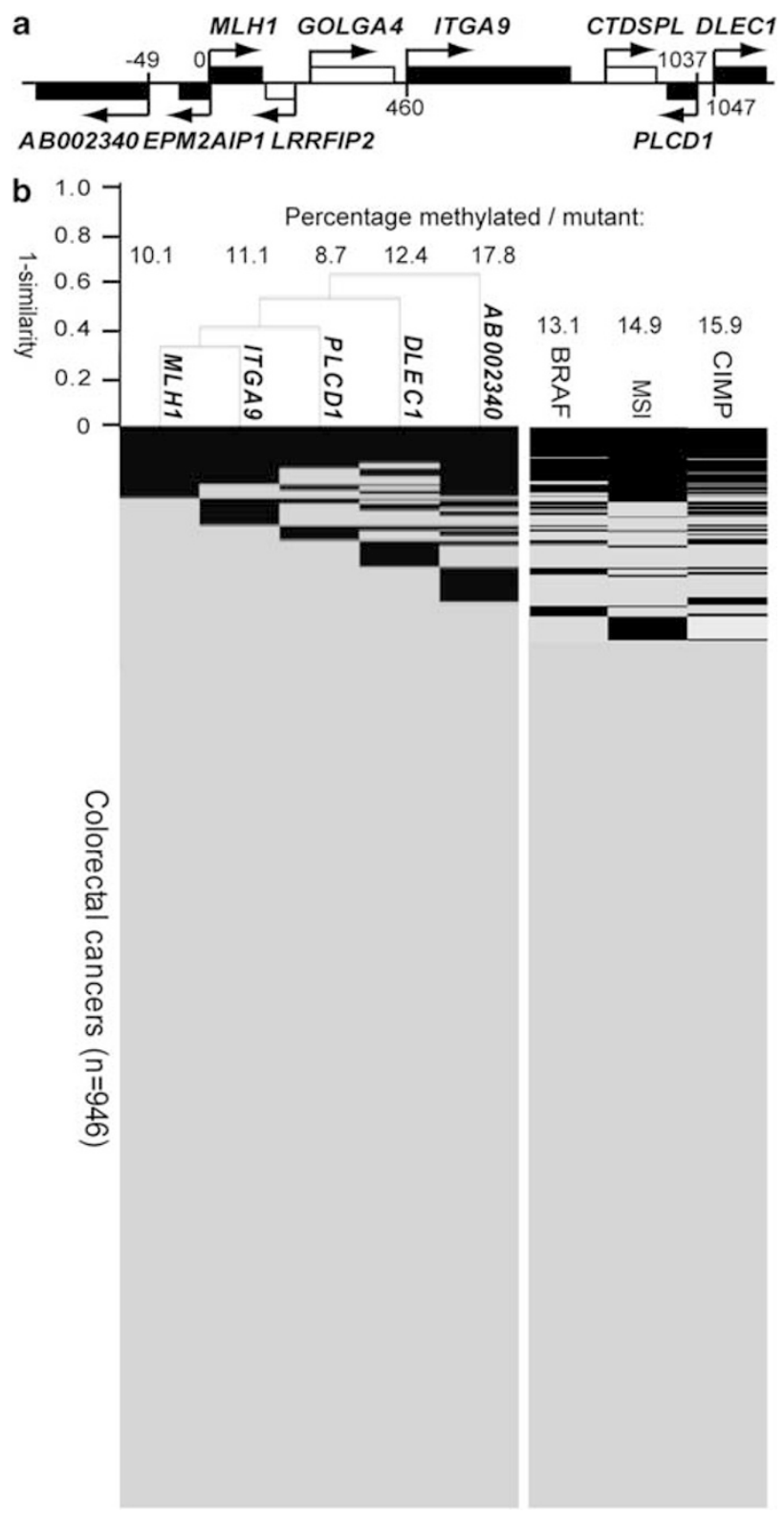
in various types of human cancers, ${ }^{14,19-23}$ suggesting that their loss of activity has a contributory role in cancer development or progression. Long-range epigenetic silencing across the 3 p22 region was strongly associated with the presence of the activating BRAF V600E mutation, consistent with previous findings for $M L H 1$ alone. ${ }^{18}$ In light of the strong association between the BRAF V600E mutation and the CIMP phenotype, as well as the independent association between this oncogenic mutation and 3p22 methylation, we hypothesized that methylation of five 3p22 genes (AB002340, MLH1, ITGA9, PLCD1 and DLEC1), individually and concomitantly, occurs in the context of CIMP + . Supporting this notion, a recent study found a strong association between CIMP + and long-range epigenetic silencing of the 2q14.2 chromosomal region in colorectal cancer, suggesting that these two epigenetic profiles may represent a unified epigenetic phenotype induced by a common mechanism, rather than distinct entities. ${ }^{24}$

In the present study, we analysed a cohort of 946 sporadic colorectal cancer cases to determine whether MLH1 methylation is associated with the germline c.-93G > A SNP genotype or methylation of the 3 p22 region, and furthermore, if methylation of the 3p22 gene cluster correlates with the CIMP + phenotype. As it is now well established that a small subset of tumours exist that are microsatellite stable, BRAF V600E mutant and CIMP,$+{ }^{14-16,25}$ we also sought evidence that this subtype of microsatellite stable cancers is concomitantly methylated at gene promoters within the $3 \mathrm{p} 22$ chromosomal region other than MLH1. Finally, to determine whether methylation of MLH1 and flanking genes, as well as the BRAF V600E mutation, might predispose to cancer development, we sought these changes in the apparently normal colorectal mucosa from a subset of the colorectal cancer cases and controls without neoplasia.

\section{Materials and methods}

\section{Patients and Samples}

A total of 946 colorectal cancer samples procured from a consecutive series of 946 individuals (mean age $69 \pm 12$ years; range 24-99 years) who had undergone curative surgical resection of colorectal adenocarcinoma at St Vincent's Hospital, Sydney, between January 1993 and November 2006 were included in this study. Individuals with a clinical diagnosis of familial adenomatous polyposis, hereditary non-polyposis colorectal cancer or inflammatory bowel disease at the time of operation were excluded. Known carriers of germline mutations of $A P C, M Y H$ and the mismatch repair genes were also excluded from the study. The clinical characteristics of individuals in this study cohort and the pathological characteristics of their cancers were obtained from medical and histopathological reports. Rightsided cancers were defined as those located proximal to the splenic flexure, and the remainder were defined as left-sided. Based on the information of the histopathological report, carcinomas were staged by the AJCC/UICC TNM system according to the sixth edition of the AJCC staging manual. ${ }^{26}$

The paired normal colorectal mucosa from 235 of the colorectal cancer cases (mean age $74 \pm 9$ years; range 51-99 years) were assessed for methylation status at MLH1. These normal colorectal mucosa samples were derived from 104 cases with a microsatellite unstable cancer, matched by gender and age ( \pm 5 years) to 131 cases with a microsatellite stable cancer. Those found positive for MLH1 methylation were further analysed for the presence of methylation at 3p22 flanking genes, as was their peripheral blood. For each of these cases, normal colorectal mucosa samples that had no detectable MLH1 methylation were selected from cases with microsatellite stable cancers matched for sex and age (within \pm 5 years). The normal colorectal mucosa from a further 13 cases (mean age $76 \pm 9$; range 63-92 years) selected at random from those whose colorectal cancers were V600E mutant and had concomitant methylation of $\geq 3$ of the five $3 \mathrm{p} 22$ genes were subsequently studied for low-level methylation of the 3 p22 genes. These were matched by sex and age ( \pm 5 years) to the normal colorectal mucosa from cases whose tumours were $B R A F$ wild type and did not have regional 3p22 methylation (mean age, $75 \pm 10$; range 58-90 years). As controls, biopsy samples of normal colonic or rectal mucosa were collected from 21 individuals without a history of colorectal cancer who had either undergone colorectal surgery or colonoscopy for a non-neoplastic disorder (mean age, $58 \pm 18$; range, 33-82 years). Genomic DNA was extracted from fresh-frozen colorectal cancer and normal colorectal mucosa specimens and peripheral blood by standard phenol-chloroform extraction. This study was approved by the human research ethics committee of St Vincent's Hospital (approval numbers H02/022 and H07/002), and informed consent was obtained from all participating individuals.

\section{Genotyping of the c.-93G $>$ A SNP (rs1800734)}

Germline DNA extracted from normal colorectal mucosa or peripheral blood was used to genotype the c.-93G > A SNP within the MLH1 promoter in 320 colorectal cancer cases, comprising 108 microsatellite unstable cases for case comparison with 212 randomly selected microsatellite stable cases, and 399 de-identified healthy controls from the Red Cross Bank. Genotyping was performed by PCR amplification of the promoter using primers $\left(5^{\prime}-3^{\prime}\right)$ AAACGAACCAATAGGAAGAGC and ACTCCCTCC GTACCAGTTCT with annealing at $56.5^{\circ} \mathrm{C}$, followed by direct sequencing using the same primers. 


\section{Methylation Analyses}

Bisulphite modification was performed on $0.5-1 \mu \mathrm{g}$ of genomic DNA using the EZ DNA methylation $\mathrm{kit}^{\mathrm{TM}}$ (Zymo Research, Orange, CA, USA) according to the manufacturer's instructions. The promoter methylation status of five 3 p22 genes, namely $A B 002340$, MLH1 (Deng-C region), ${ }^{27}$ ITGA9, PLCD1 and DLEC1, was assessed by real-time quantitative methylationspecific PCR assays, which have an analytical sensitivity of 0.1 methylated alleles (Table 1). Reactions were performed in $20 \mu \mathrm{l}$ volumes containing $2 \mu \mathrm{l}$ (50-100 ng) of bisulphite-converted DNA, $1 \times$ IQ SybrGreen supermix (Bio-Rad, Hercules, CA, USA) and $0.3 \mu \mathrm{M}$ of the respective forward and reverse primers, listed in Supplementary Table 2. All real-time methylation-specific PCR reactions were performed using a $\mathrm{MyIQ}^{\mathrm{TM}}$ Single-Colour Real-Time PCR machine (Bio-Rad). Cycling conditions were: $95^{\circ} \mathrm{C}$ for $6 \mathrm{~min}$, followed by 40 cycles at $94{ }^{\circ} \mathrm{C}$ for $30 \mathrm{~s}$, the respective annealing temperature for $30 \mathrm{~s}$ (Table 1), and extension at $72^{\circ} \mathrm{C}$ for $30 \mathrm{~s}$. The fluorescence output signal was measured in the fourth step of each cycle $\left(>72{ }^{\circ} \mathrm{C}\right)$ held for $30 \mathrm{~s}$ to exclude potential signals from primer dimerization. Reactions that amplify a control template $M y o D$ irrespective of its methylation status were used to normalize for DNA input. For a given sample, the starting copy number of the methylated 3p22 genes and $M y o D$ genes was determined in triplicate by interpolation against the respective standard curves consisting of serial dilutions of plasmids of known copy number harbouring the target sequences. The copy numbers were used to determine the percentage of methylation reference (PMR) values with reference to completely methylated in vitro human DNA (Chemicon, Temecula, CA, USA), as previously described. ${ }^{28}$ Cancers were considered methylated when PMR values were $>4.0$, as this threshold has previously been shown to correlate with loss of gene expression in a study that correlated the distribution of PMR to protein expression by immunohistochemistry. ${ }^{29}$ For normal colorectal mucosa samples, PMR values were analysed as continuous variables given that DNA methylation is likely to occur at lower levels within an apparently normal field of colorectal crypts. An analysis of CIMP status in colorectal cancer samples was performed using MethyLight on a set of five CIMP markers as previously described. ${ }^{14}$ Cancers were considered CIMP + when $\geq 3 / 5$ (60) markers showed intensities of methylation at $\mathrm{PMR}>4.0 .^{16}$

\section{Microsatellite Instability, $B R A F$ and $K R A S$ Mutation Status}

Microsatellite stability status was determined using two mononucleotide markers BAT25 and BAT26 as well as three dinucleotide markers D5S346, D2S123 and D17S250, as previously described. ${ }^{30}$ A carcinoma sample was classified as having microsatellite instability when two or more markers demonstrated instability in the tumour DNA compared with the corresponding constitutional DNA. Presence of the common BRAF V600E and KRAS codon 12 and 13 mutations in colorectal cancer samples were detected by pyrosequencing, as previously described. ${ }^{31}$ For normal colorectal mucosa samples, BRAF V600E mutation status was determined by the highly sensitive allele-specific real-time PCR as previously described. ${ }^{32}$ A sample was called positive for BRAF V600E mutation only when the cycle difference between the wild-type and mutant reactions $(\Delta \mathrm{Ct})$ was $<11$ (Supplementary Figure 2), as previously validated. ${ }^{31}$

Table 1 Primer sequences and conditions for quantitative methylation-specific PCR (qMSP) of the CpG-island promoters of the 3p22 genes

\begin{tabular}{|c|c|c|c|c|}
\hline Gene & & Sequence $\left(5^{\prime}-3^{\prime}\right)$ & Size (bp) & $\operatorname{Tm}\left({ }^{\circ} \mathrm{C}\right)$ \\
\hline MLH1 & Forward & CGTTAAGTATTTTTTTCGTTTTGCG & 214 & 61 \\
\hline C-region & Reverse & TAAATCTCTTCGTCCCTCCCTAAAACG & & \\
\hline \multirow[t]{2}{*}{ AB002340 } & Forward & GCGGTTCGGTTATTTAGTCG & 146 & 61 \\
\hline & Reverse & CCACTCAACAACGACGTACAC & & \\
\hline \multirow[t]{2}{*}{ ITGA9 } & Forward & GTCGTTTTTGTGTTCGTTTTTAGC & 109 & 64 \\
\hline & Reverse & CCGAAACGAAAACTCTACGCCTAAAC & & \\
\hline \multirow[t]{2}{*}{ PLCD1 } & Forward & GGGCGTCGGATTTTATACG & 133 & 61 \\
\hline & Reverse & GAACCGCGAACCCTATCATTAC & & \\
\hline \multirow[t]{2}{*}{ DLEC1 } & Forward & GTAGTTTGCGTTGGCGTAGC & 103 & 63 \\
\hline & Reverse & ACGAAAAACGCCGATAAACA & & \\
\hline \multirow{2}{*}{$\begin{array}{l}\text { MyoD } \\
\text { control }\end{array}$} & Forward & CСААСТССАААТССССТСТСТАТ & 163 & 61 \\
\hline & Reverse & TGATTAATTTAGATTGGGTTTAGAGAAGGA & & \\
\hline
\end{tabular}

Tm, annealing temperature. 


\section{Statistical Analyses}

Categorical variables were compared using the $\chi^{2}$ test or Fisher's exact test. The Mann-Whitney $U$ test was used to compare continuous variables that were not normally distributed. Multivariate analysis was performed using multivariate logistic regression analysis. Samples with one or more missing data points were excluded from the multivariate analysis. Associations were considered significant when $P \leq 0.05$ (two sided). These analyses were performed using the SPSS statistical package, version 18.0 (SPSS, Chicago, IL, USA). Multiple hypotheses testing using the Holm's test was performed to correct for false-positive results where applicable. Hierarchical clustering analysis was performed using the Hierarchical Clustering Explorer version 3.5 (University of Maryland), available online at http://www.cs.umd.edu/hcil/hce. An average linkage method using Manhattan distance was used.

\section{Results}

Lack of Association between MLH1 Methylation and the c.-93G $>$ A Promoter SNP

Within a consecutive series of 946 sporadically arising colorectal carcinoma, methylation of the 'Deng-C region' of the MLH1 promoter was identified in $10.1 \%$ of colorectal cancers, including $68.1 \%$ of microsatellite unstable tumours, and correlated closely with microsatellite instability, the CIMP + phenotype, presence of the BRAF V600E mutation, right-sided location, mucinous histology, higher tumour grade, early stage, increased age and female gender (Table 2), consistent with previous findings. ${ }^{14-15,33}$ Genotyping of the c.-93G > A SNP (rs1800734) within the MLH1 promoter in 320 colorectal cancer cases and 399 healthy controls showed that the genotypes were in Hardy-Weinberg equilibrium for both populations and demonstrated similar allele frequencies ('A' allele frequency: $29.4 \%$ in cases and $25.7 \%$ in healthy controls). No association was found between the G>A SNP genotype and a diagnosis of cancer when compared with the healthy control population (Table 3). We found no association between MLH1 methylation or microsatellite instability in a case-by-case comparison, when the AA and GA genotypes were combined into one category and compared with the homozygous G genotype (Table 3). Similarly, there was no association with the A allele when the three genotypes were separated (AA, GA and GG, data not shown). Finally, there was no correlation between the G>A SNP genotype (with AA and AG combined) and MLH1 methylation within the microsatellite instability or CIMP + groups, either (Table 3), arguing against an underlying role for this SNP genotype in inducing methylation of MLH1 in this sporadic colorectal cancer cohort.
Concomitant Methylation of a Cluster of 3p22 Genes in a Subset of Sporadic Colorectal Cancers

To determine whether our previous finding of concomitant methylation of a cluster of 3 p22 genes in sporadic colorectal cancer was consistent in this large cohort, the methylation status of four genes flanking $M L H 1$ previously found to be subject to CpG island methylation was determined (Figure 1a). The most frequently methylated gene was AB002340, followed by DLEC1, ITGA9, MLH1 and finally, PLCD1 (Table 2 and Figure 1b). A significant association was found between methylation of each 3 p22 gene individually and that of the four other genes $(P<0.0001$; Table 4$)$, confirming that methylation typically occurred in a cluster in the $3 p 22$ region. Hierarchical clustering showed that methylation of MLH1 concurred most frequently with the nearby ITGA9 gene (Figure 1b), although these two genes are separated by two genes (LRRFIP2 and GOLGA4) that are not prone to methylation in colorectal cancer (Figure 1a).

\section{Simultaneous Methylation of $\geq 3$ 3p22 Genes Correlates Closely with the Presence of the $B R A F$ V600E Mutation, Microsatellite Instability and CIMP +}

The proportion of sporadic colorectal cancers showing different numbers of methylated $3 \mathrm{p} 22$ genes stratified by BRAF V600E mutation, microsatellite stability status and CIMP status is shown in Figures 2-4, respectively. The majority of cancers showed heavy methylation at multiple loci $(\geq 3)$ in cancers also demonstrating BRAF V600E mutation (Figure 2), microsatellite instability (Figure 3) and the CIMP + phenotype (Figure 4), whereas the percentage of BRAF wild-type, microsatellite stable and CIMP - cancers decreased consistently with increasing number of methylated 3p22 genes. Consistent with these findings, colorectal cancers were dichotomized into those with methylation at 3-5 of the five $3 p 22(10.8 \%)$ genes, designated positive for regional 3p22 methylation, and those with methylation at $0-2(89.2 \%)$, designated negative for regional methylation. On this basis, regional 3p22 methylation was found predominantly in colorectal cancers with BRAF V600E mutation (Figure 5). Among BRAF mutant cancers, regional 3p22 methylation was most frequently found in those that demonstrated concomitant CIMP + and microsatellite instability. Regional 3p22 methylation was found in a small number of BRAF mutant cancers that showed either CIMP +/microsatellite stable or CIMP-/microsatellite instability phenotypes, and was entirely absent in cancers that were both CIMPand microsatellite stable. Although regional 3p22 methylation was found predominantly in microsatellite unstable tumours, 15 (1.6\%) colorectal cancers methylated at $\geq 33 \mathrm{p} 22$ loci excluding MLH1 were microsatellite stable, suggesting that regional 
Table 2 Associations between clinical and molecular characteristics of colorectal cancer cases and the presence of methylation at MLH1 and other 3p22 genes, individually and as a cluster

\begin{tabular}{|c|c|c|c|c|c|c|c|}
\hline \multirow[t]{2}{*}{ Clinical/molecular characteristic } & \multicolumn{7}{|c|}{ Chromosome region $3 p 22$ gene methylation } \\
\hline & AB002340 & MLH1 & ITGA9 & PLCD1 & DLEC1 & $\geqslant 3 / 53 p 22$ loci & Total cases (\%) \\
\hline Methylated cases (\%) & $169(17.9)$ & $96(10.1)$ & $105(11.1)$ & $82(8.7)$ & $117(12.4)$ & $102(10.8)$ & 946 \\
\hline Mean age \pm s.d. & $72 \pm 11$ & $75 \pm 10$ & $74 \pm 10$ & $73 \pm 10$ & $70 \pm 11$ & $74 \pm 10$ & 946 \\
\hline$P$-value & $P<\mathbf{0 . 0 0 0 1}$ & $P<\mathbf{0 . 0 0 0 1}$ & $P<\mathbf{0 . 0 0 0 1}$ & $P<0.0001$ & $P=1.00$ & $P<0.0001$ & \\
\hline Sex & & & & & & & 946 \\
\hline Male $(\%)^{a}$ & $67(12.6)$ & $34(6.4)$ & $38(7.2)$ & $31(5.8)$ & $50(9.4)$ & $32(6.0)$ & $415(43.9)$ \\
\hline Female $(\%)$ & $102(24.6)$ & $62(14.9)$ & $67(16.1)$ & $51(12.3)$ & 67 (16.1) & $70(16.9)$ & $531(56.1)$ \\
\hline$P$-value & $P<0.0001$ & $P<0.0001$ & $P<0.0001$ & $P<0.0001$ & $P<0.0001$ & $P<0.0001$ & \\
\hline OR $(95 \% \mathrm{CI})$ & $2.3(1.6-3.2)$ & $2.6(1.7-4.0)$ & $2.5(1.6-3.8)$ & $2.3(1.4-3.6)$ & $1.9(1.3-2.7)$ & $3.1(2.0-4.9)$ & \\
\hline Tumour site & & & & & & & 945 \\
\hline Right sided (\%) & $122(36.0)$ & $80(23.6)$ & $81(23.9)$ & $61(18.0)$ & $73(21.5)$ & $83(24.5)$ & $339(35.9)$ \\
\hline Left sided $(\%)^{\mathrm{a}}$ & $47(7.8)$ & $16(2.6)$ & $24(4.0)$ & $21(3.5)$ & $44(7.3)$ & $19(3.1)$ & $606(64.1)$ \\
\hline$P$-value & $P<0.0001$ & $P<0.0001$ & $P<0.0001$ & $P<0.0001$ & $P<0.0001$ & $P<0.0001$ & \\
\hline OR $(95 \%$ CI $)$ & $6.7(4.6-9.7)$ & $11.4(6.5-19)$ & $7.6(4.7-12)$ & $6.1(3.6-10)$ & $3.5(2.3-5.2)$ & $10(5.9-16.8)$ & \\
\hline Tumour type & & & & & & & 942 \\
\hline Mucinous (\%) & $71(36.8)$ & $55(28.5)$ & $56(29.0)$ & $39(20.2)$ & $51(26.4)$ & $58(30.1)$ & $193(20.5)$ \\
\hline Non-mucinous $(\%)^{\mathrm{a}}$ & 98 (13.1) & $41(5.5)$ & $49(6.5)$ & $43(5.7)$ & $66(8.8)$ & $44(5.9)$ & 749 (79.6) \\
\hline$P$-value & $P<0.0001$ & $P<0.0001$ & $P<0.0001$ & $P<0.0001$ & $P<0.0001$ & $P<0.0001$ & \\
\hline OR (95\% CI) & $3.9(2.7-5.5)$ & $6.9(4.4-10)$ & $5.8(3.8-8.9)$ & $4.2(2.6-6.6)$ & $3.7(2.5-5.6)$ & $6.9(4.5-11)$ & \\
\hline Tumour grade & & & & & & & 945 \\
\hline Low grade $(\%)^{\mathrm{a}}$ & $118(14.6)$ & $58(7.2)$ & $68(8.4)$ & $52(6.4)$ & $78(9.6)$ & $61(7.5)$ & $810(85.7)$ \\
\hline High grade (\%) & $51(37.8)$ & $38(28.1)$ & $37(27.4)$ & $30(22.2)$ & $39(28.9)$ & $41(30.4)$ & $135(14.3)$ \\
\hline$P$-value & $P<0.0001$ & $P<0.0001$ & $P<0.0001$ & $P<0.0001$ & $P<0.0001$ & $P<0.0001$ & \\
\hline OR (95\% CI) & $3.6(2.4-5.3)$ & $5.1(3.2-8.1)$ & $4.1(2.6-6.5)$ & $4.2(2.5-6.8)$ & $3.8(2.5-5.9)$ & $5.3(3.4-8.4)$ & \\
\hline TNM stage & & & & & & & 946 \\
\hline I (\%) & 33 (17.9) & $20(10.9)$ & $22(12.0)$ & $15(8.2)$ & $26(14.1)$ & 19 (10.3) & $184(19.5)$ \\
\hline II $(\%)$ & $65(19.9)$ & $47(14.4)$ & $47(14.4)$ & $38(11.6)$ & $49(15.0)$ & $49(15.0)$ & $328(34.7)$ \\
\hline III (\%) & $53(17.4)$ & $25(8.2)$ & $29(9.5)$ & $22(7.2)$ & $32(10.5)$ & $28(9.2)$ & $301(31.8)$ \\
\hline IV (\%) & $18(13.8)$ & $4(3.1)$ & $7(5.4)$ & $7(5.4)$ & $10(7.7)$ & $6(4.6)$ & $133(14.1)$ \\
\hline$P$-value & $P=1.0$ & $P=\mathbf{0 . 0 1 4}$ & $P=0.231$ & $P=0.714$ & $P=0.728$ & $P=0.056$ & \\
\hline Microsatellite status & & & & & & & 946 \\
\hline MSI (\%) & $95(67.4)$ & $96(68.1)$ & $76(53.9)$ & $60(42.6)$ & $69(48.9)$ & $87(61.7)$ & $141(14.9)$ \\
\hline $\operatorname{MSS}(\%)^{\mathrm{a}}$ & $74(9.2)$ & $0(0.0)$ & $29(3.6)$ & $22(2.7)$ & $48(6.0)$ & $15(1.9)$ & $805(85.1)$ \\
\hline$P$-value & $P<0.0001$ & $P<0.0001$ & $P<0.0001$ & $P<0.0001$ & $P<0.0001$ & $P<0.0001$ & \\
\hline OR $(95 \% \mathrm{CI})$ & $20(13-32)$ & $18.9(14-25)$ & $31.3(19-51)$ & $26(15-45)$ & $15(9.7-23)$ & $85(46-157)$ & \\
\hline KRAS codon $12 / 13$ & & & & & & & 946 \\
\hline Mutant $(\%)^{a}$ & $31(10.3)$ & $5(1.7)$ & $11(3.7)$ & $7(2.3)$ & $13(4.3)$ & $3(1.0)$ & $300(31.7)$ \\
\hline Wild type (\%) & $138(21.4)$ & $91(14.1)$ & $94(14.6)$ & 75 (11.6) & $104(16.1)$ & $99(15.3)$ & $646(68.3)$ \\
\hline$P$-value & $P<0.0001$ & $P<0.0001$ & $P<0.0001$ & $P<0.0001$ & $P<0.0001$ & $P<0.0001$ & \\
\hline OR (95\% CI) & $2.4(1.5-3.6)$ & $9.7(3.9-24)$ & $4.5(2.4-8.5)$ & $5.4(2.5-12)$ & $4.2(2.3-7.7)$ & $18(5.6-57)$ & \\
\hline$B R A F$ V600E & & & & & & & 944 \\
\hline Mutant (\%) & $106(85.5)$ & $76(61.3)$ & $80(64.5)$ & $61(49.2)$ & $72(58.1)$ & $86(69.4)$ & $124(13.1)$ \\
\hline Wild type $(\%)^{a}$ & $62(7.6)$ & $19(2.3)$ & $25(3.0)$ & $20(2.4)$ & $45(5.5)$ & $15(1.8)$ & $820(86.9)$ \\
\hline$P$-value & $P<0.0001$ & $P<0.0001$ & $P<0.0001$ & $P<0.0001$ & $P<0.0001$ & $P<0.0001$ & \\
\hline OR $(95 \% \mathrm{CI})$ & $72(41-126)$ & $67(37-119)$ & $58(34-99)$ & $39(22-68)$ & $24(15-38)$ & $122(64-129)$ & \\
\hline CIMP & & & & & & & 944 \\
\hline Positive (\%) & 125 (83.3) & $82(54.7)$ & $88(58.7)$ & $69(46.0)$ & $79(52.7)$ & $94(62.7)$ & $150(15.9)$ \\
\hline Negative $(\%)^{\mathrm{a}}$ & $43(5.4)$ & $13(1.6)$ & $16(2.0)$ & $12(1.5)$ & $37(4.7)$ & $7(0.9)$ & $794(84.1)$ \\
\hline$P$-value & $P<0.0001$ & $P<0.0001$ & $P<0.0001$ & $P<0.0001$ & $P<0.0001$ & $P<0.0001$ & \\
\hline OR $(95 \% \mathrm{CI})$ & $87(52-148)$ & $72(38-136)$ & $69(38-125)$ & $56(29-107)$ & $23(14-36)$ & $189(83-426)$ & \\
\hline
\end{tabular}

TNM, tumour, node and metastasis; MSI, microsatellite instability; MSS, microsatellite stable; CIMP, CpG island methylator phenotype.

${ }^{\mathrm{a}}$ Indicates the referent category, where applicable.

The $P$-value for the comparison of mean age between groups was obtained using the Mann-Whitney $U$ test. The $P$-values were determined using either $\chi^{2}$ test or Fisher's exact test for all other characteristics. All $P$-values were adjusted using Holm's test. Where any adjusted $P$-value exceeded 1, it was set to 1.0. Significant $P$-values are highlighted in bold.

The percentage of gene methylation given in parentheses relates to the frequency of methylation within the pertinent clinical or molecular category. Odds ratios (ORs) and 95\% confidence intervals (95\% CIs) are shown for the positively related variable. 
Table 3 Lack of association between MLH1 SNP c.-93G > A (rs1800734) genotype and MLH1 methylation or microsatellite instability status

\begin{tabular}{|c|c|c|c|c|}
\hline \multirow{2}{*}{ Clinical/molecular characteristic } & \multicolumn{4}{|c|}{ SNP rs1800734 genotype } \\
\hline & Total cases (\%) & $G G$ & $G A / A A$ & $P$-value, OR (95\% CI) \\
\hline \multicolumn{5}{|l|}{ Case-control study } \\
\hline CRC cases $(\%)$ & 320 & $160(50.0)$ & $160(50.0)$ & $P=0.12,0.9(0.75-1.0)$ \\
\hline Healthy controls (\%) & 399 & $223(53.3)$ & $176(44.1)$ & \\
\hline \multicolumn{5}{|l|}{ CRC cases only } \\
\hline MLH1 & 320 & & & \\
\hline Methylated (\%) & $85(26.5)$ & $41(49)$ & $44(51)$ & $P=0.7,1.1(0.74-1.6)$ \\
\hline Unmethylated (\%) & $241(75.3)$ & $119(52)$ & $122(48)$ & \\
\hline MSI status & 320 & & & \\
\hline MSI (\%) & $108(33.8)$ & $54(50)$ & $54(50)$ & $P=1.0,1.0(0.74-1.4)$ \\
\hline $\operatorname{MSS}(\%)$ & $212(66.3)$ & $106(50)$ & $106(50)$ & \\
\hline Within MSI group & 108 & & & \\
\hline MLH1 methylated & $79(73.1)$ & $41(39.5)$ & $38(39.5)$ & $P=0.52,1.1(0.9-1.4)$ \\
\hline MLH1 unmethylated & $29(26.9)$ & $13(14.5)$ & $16(14.5)$ & \\
\hline Within CIMP+ group & 90 & $50(50.6)$ & $40(44.4)$ & $P=0.34,0.9(0.7-1.1)$ \\
\hline MLH1 methylated & $70(77.8)$ & $37(74.0)$ & $33(82.5)$ & \\
\hline MLH1 unmethylated & $20(22.2)$ & $13(26.0)$ & 7 (17.5) & \\
\hline
\end{tabular}

CRC, colorectal cancer; MSI, microsatellite instability; MSS, microsatellite stable; CIMP+, positive for CpG island methylator phenotype. $P$-values are indicated for relationships between clinical and molecular categories and GG homozygotes or GA/AA genotypes combined. Odds ratio (OR) and $95 \%$ confidence intervals (CIs) relate to the risk of the top-listed variable.

Table 4 Frequency of association between promoter methylation of each 3 p22 gene and that of other 3 p22 genes in sporadic colorectal cancer

\begin{tabular}{lcccccccccc}
\hline MLH1 & $\mathrm{U}$ & 768 & 82 & & & & & & \\
& $\mathrm{M}$ & 9 & $87^{*}$ & & & & & & \\
ITGA9 & $\mathrm{U}$ & 761 & 80 & 819 & 22 & & & & \\
& $\mathrm{M}$ & 16 & $89^{*}$ & 31 & $74^{*}$ & & & & \\
PLCD1 & $\mathrm{U}$ & 768 & 96 & 825 & 39 & 814 & 50 & & \\
& $\mathrm{M}$ & 9 & $73^{*}$ & 25 & $57^{*}$ & 27 & $55^{*}$ & & \\
DLEC1 & $\mathrm{U}$ & 739 & 90 & 798 & 31 & 789 & 40 & 803 & 26 \\
& $\mathrm{M}$ & 38 & $79^{*}$ & 52 & $65^{*}$ & 52 & $65^{*}$ & 61 & $56^{*}$ \\
& \multicolumn{1}{c}{$\mathrm{U}$} & $\mathrm{M}$ & $\mathrm{U}$ & $\mathrm{M}$ & $\mathrm{U}$ & $\mathrm{M}$ & $\mathrm{U}$ & $\mathrm{M}$ \\
& \multicolumn{1}{c}{$\mathrm{M} 002340$} & $M L H 1$ & ITGA9 & PLCD1 \\
\hline
\end{tabular}

Methylation: U, unmethylated; M, methylated.

${ }^{*} P<0.0001$ ( $\chi^{2}$ test).

Significant associations were observed between methylation of any one gene with that of all other genes.

3p22 methylation is not specific to microsatellite instability (Figure 5).

\section{Association between Methylation of Individual 3p22 Genes, Regional 3p22 Methylation and Clinicopathological and Molecular Features}

The association between promoter methylation of 3 p22 genes individually or as a cluster of $\geq 3 / 5$ loci and other clinicopathological and molecular features of colorectal cancer is summarized in Table 2. On an individual basis, significant correlations were observed between methylation at each of the four

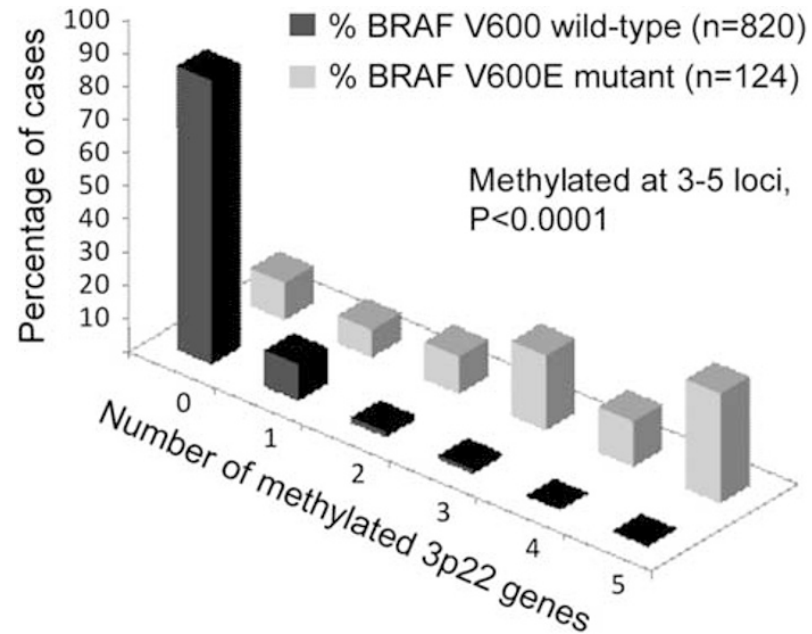

Figure 2 Concomitant methylation of multiple $3 \mathrm{p} 22$ genes and BRAF V600E mutation in colorectal carcinoma. Histogram showing the distribution of colorectal cancers with promoter methylation of $0,1,2,3,4$ and 5 genes within the $3 p 22$ chromosomal domain stratified by BRAF mutation status.

3p22 genes flanking $M L H 1$ and female gender, right sidedness of tumours, mucinous histology, low tumour grade, wild-type KRAS, BRAF V600E mutant, microsatellite instability and CIMP + phenotype (all $P<0.05$ ), consistent with findings for MLH1 methylation alone (Table 2). The presence of methylation of the 3 p22 genes was also associated with older age, with the exception of DLEC1 methylation $(P=1.00)$. When categorized by regional 3p22 methylation (methylation at $\geq 3 / 5$ loci), 


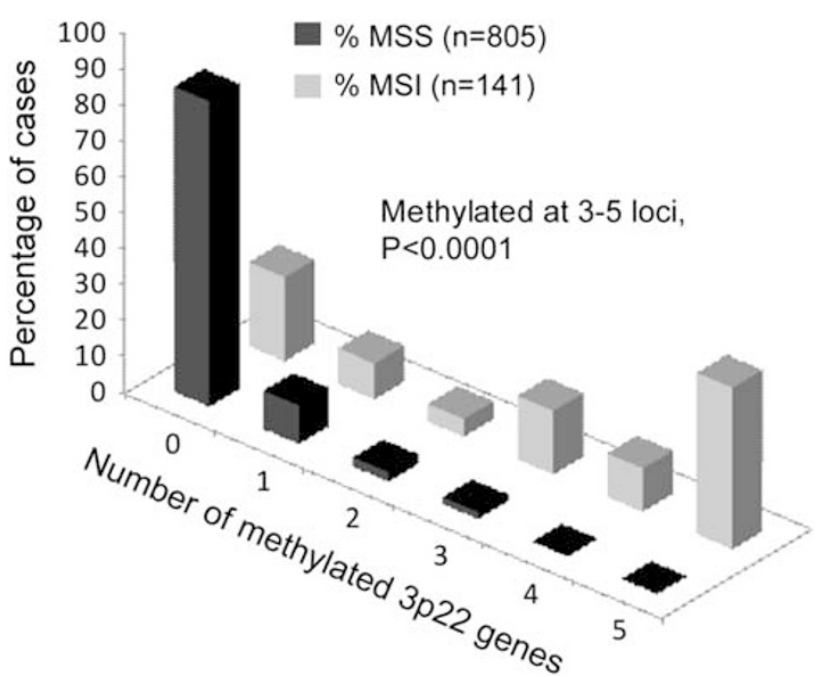

Figure 3 Concomitant methylation of multiple 3p22 genes and the microsatellite instability phenotype in colorectal carcinoma. Histogram showing the distribution of colorectal cancers with promoter methylation of $0,1,2,3,4$ and 5 genes within the 3p22 chromosomal domain stratified by microsatellite stability status. MSI, microsatellite unstable; MSS, microsatellite stable.

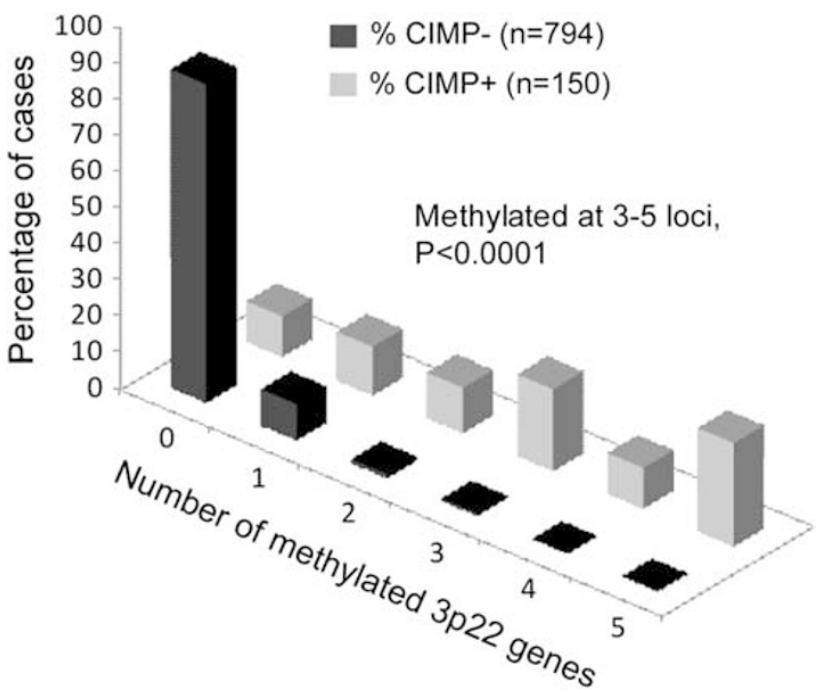

Figure 4 Concomitant methylation of multiple 3p22 genes and the $\mathrm{CpG}$ island methylator phenotype (CIMP) in colorectal carcinoma. Histogram showing the distribution of colorectal cancers with promoter methylation of $0,1,2,3,4$ and 5 genes within the 3p22 chromosomal domain stratified by CIMP status.

significant correlations were observed between cancers demonstrating clustered 3p22 methylation and older age, female gender, right sidedness of cancers, mucinous histology, high tumour grade, wild-type KRAS, BRAF V600E mutation, microsatellite instability and CIMP + (all $P<0.01$ ). Multivariate analysis of clinicopathological and molecular associations found BRAF V600E mutation, CIMP + and mucinous histology to be independent predictors of regional 3p22 methylation (Table 5).

\section{Detection of Low-Level Methylation of MLH1 and Other 3p22 Genes and BRAF V600E Mutation in the Normal Colorectal Mucosa of a Small Number of Colorectal Cancer Cases}

Using sensitive real-time quantitative methylation specific PCR capable of detecting low levels of methylation (0.01), normal colorectal mucosa samples from 104 cases with microsatellite unstable carcinoma, 131 cases with microsatellite stable cancer and 21 individuals without neoplasia were screened for the presence of MLH1 methylation. No methylation was detected in normal colorectal mucosa from individuals with sporadic microsatellite stable colorectal cancer or those without neoplasia (PMR $=0$; Figure 6). Interestingly, however, lowdensity $M L H 1$ methylation (median $\mathrm{PMR}=0.54$; range 0.17-3.7) was detected in the normal colorectal mucosa samples of seven $(\leq 7 \%)$ cases with sporadic microsatellite unstable carcinoma (Figures 6a and 7). Higher levels of MLH1 methylation were found in the corresponding cancers of each of these individuals (median $\mathrm{PMR}=58.94$; range 24.33-93.13; Figures 6 and $7 \mathrm{a}$ ). The presence of allelic methylation was confirmed in all seven normal colorectal mucosa samples by cloning and sequencing of individual amplicons from the methylation specific PCR products, with some alleles showing partial methylation and others showing complete methylation (Figure 7b). No methylation was detected in their peripheral blood lymphocytes (data not shown), suggesting that methylation was somatically acquired and localized, as opposed to constitutional, such as that found in carriers of MLH1 epimutations. ${ }^{34-37}$ In the tumours of each of these seven cases, at least one additional gene within 3p22 was concomitantly methylated with MLH1 (Figure 6). In five cases, the tumours were BRAF V600E mutant and in four the tumours were CIMP + (Table 6). Therefore, to determine if additional genes within 3 p22 were also methylated in the normal colonic mucosa of these microsatellite unstable cases, and if the BRAF V600E mutation might have preceded this epigenetic event, real-time methylation-specific PCR of the other four 3p22 loci and sensitive real-time allele-specific PCR of BRAF were performed. Indeed, low levels of methylation of additional 3 p22 genes were found in the normal colonic mucosa of five of the seven cases (Figure 6). The finding of dense methylation affecting a small number of alleles was confirmed by clonal sequencing of the real-time methylation-specific PCR products (Figure 8). Furthermore, the presence of the BRAF V600E mutation was detected in the normal colonic mucosa of four of the latter five cases (Figure 6 and Supplementary Figure 2), each with correspondingly BRAF mutant, CIMP + tumours (Table 6). In contrast, no methylation or BRAF mutation was detected in the normal colonic mucosa of seven microsatellite stable cases matched by gender and age ( \pm 5 years) whose tumours were BRAF wild type and devoid of 


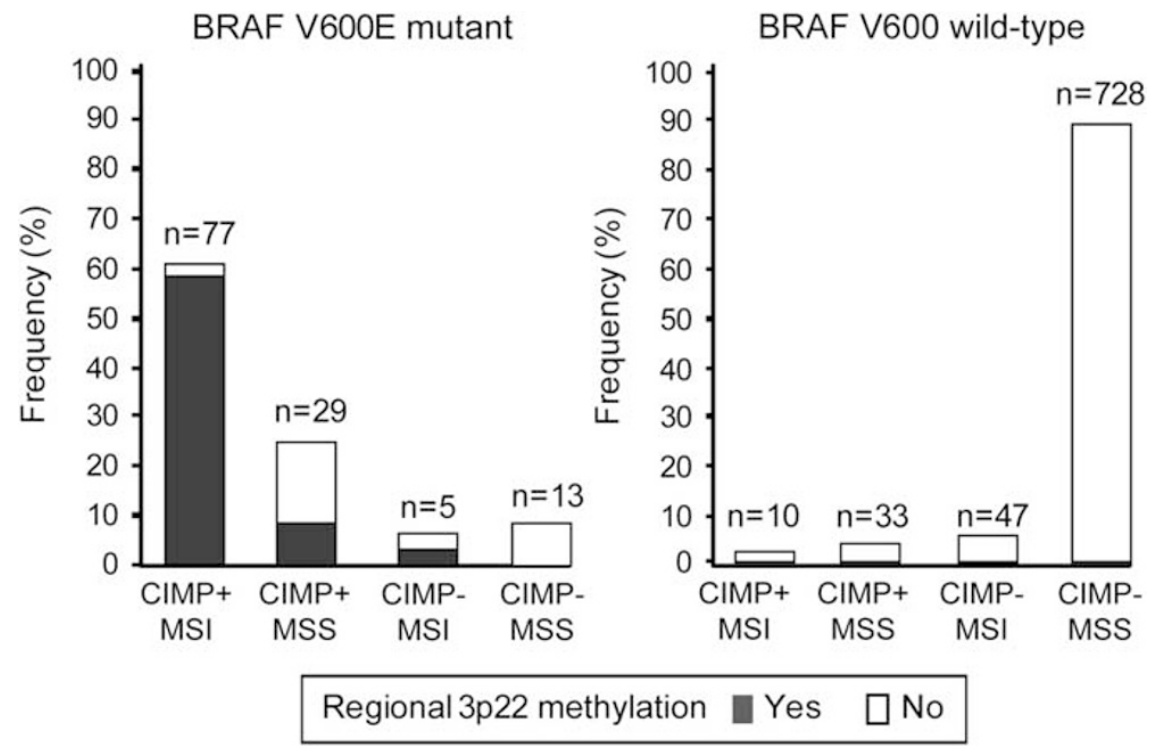

Figure 5 Distribution of regional 3p22 methylation in colorectal cancers stratified by BRAF V600E mutation, CIMP and microsatellite stability status. Only colorectal cancers for which all data points were available $(n=942)$ were included. Numbers for each category are expressed as a percentage of the total sample number within each group (BRAF mutant, $n=124 ;$ or wild type, $n=818$ ). MSS, microsatellite stable; MSI microsatellite unstable.

Table 5 Independent predictors of regional 3p22 methylation by multivariate logistic regression

\begin{tabular}{lcc}
\hline $\begin{array}{l}\text { Clinicopathological/molecular } \\
\text { feature }\end{array}$ & OR (95\% CI) & P-value \\
\hline Age & $1.0(1.0-1.1)$ & 0.708 \\
Sex (female) & $2.2(1.0-4.8)$ & 0.132 \\
Tumour site (right sided) & $1.7(0.7-3.9)$ & 0.747 \\
Tumour type (mucinous) & $3.3(1.5-7.3)$ & $\mathbf{0 . 0 0 9}$ \\
Tumour grade (low grade) & $2.76(1.1-6.2)$ & 0.108 \\
KRAS codon 12 or 13 mutation & $2.4(0.5-10.2)$ & 0.750 \\
(wild type) & $29.2(10.6-80.7)$ & $<\mathbf{0 . 0 0 0 1}$ \\
CIMP (+) & $8.5(3.42-23.2)$ & $<\mathbf{0 . 0 0 0 1}$ \\
BRAF (V600E mutant) &
\end{tabular}

Odds ratio (OR) and 95 confidence interval (95\% CI) as well as $P$-values obtained using the analysis are shown.

Significant $P$-values obtained after correction using Holm's test are highlighted in bold.

Only variables with $P<0.05$ in the univariate analyses (Table 2) were included in the multivariate analysis. Microsatellite stability status was not included as this feature is likely to be a downstream event associated with regional 3p22 methylation. 3p22 methylation (Figure 6). These data show that low-level methylation of $3 \mathrm{p} 22$ genes and the BRAF V600E mutation were more common in the normal colorectal mucosa samples of individuals who had cancers showing the same molecular profile. Interestingly, although none of the seven microsatellite unstable colorectal cancer cases with MLH1 methylation in their normal colonic mucosa had a synchronous colorectal cancer, the four cases with combined methylation of additional 3p22 genes and the BRAF V600E mutation in their normal colorectal mucosa did have a clinical history of hyperplastic polyps, and three of these additionally presented with serrated and/or conventional polyps (Table 6).

We extended our study of methylation of $3 \mathrm{p} 22$ genes flanking $M L H 1$ and the presence of the BRAF V600E mutation in normal colorectal mucosa to determine the frequency of this event in colorectal cancer cases and to elucidate the chronology between these genetic and epigenetic events. To

Figure 6 The presence of regional 3p22 methylation and BRAF V600E mutation in colorectal cancer and normal colorectal mucosa samples. Horizontal lines represent the carcinoma (C) or normal colorectal mucosa (N), as labelled, for each individual. The gender, (M, male and F, female) and age of cancer onset in years (y) is given for each individual. Genes, as labelled, are represented as rectangles with methylation or mutation density depicted by shading from white, through grey, to black, as indicated in the key. The degree of methylation, as measured by quantitative real-time methylation-specific PCR, is expressed as the percentage of methylated reference (PMR). BRAF mutation status was measured by real-time allele-specific PCR. There is an inverse correlation between the value of the difference in cycle threshold (dCt) between the mutant and wild-type alleles and level of mutant allele detected. (a) Seven of 104 microsatellite unstable colorectal cancer cases in whom MLH1 methylation was detectable in the paired normal colonic mucosa (top panel), with seven colorectal cancer cases without MLH1 methylation in their tumours matched by age ( \pm 5 years) and gender as controls (lower panel). The BRAF V600E mutation was also detected in the normal colonic mucosa of four (N1-4) of the five cases whose tumours were also mutant (C1-5). (b) Comparative methylation profile of carcinoma and normal colorectal mucosa in cases with regional methylation (of $\geq 3$ of the five 3p22 genes) and BRAF V600E mutation in their tumours (upper panel), compared with cases whose cancers were BRAF wild type and had no 'regional' 3 p22 methylation matched by age ( \pm 5 years) and gender. (c) Normal colorectal mucosa from controls without neoplasia. 
this end, the normal colorectal mucosa samples from 13 additional individuals who had cancers with dense regional 3p22 methylation and concomitant BRAF V600E mutation were screened. Methylation was detected in just three of these normal colonic mucosa samples, and this was confined to the ITGA9 and/or PLCD1 promoters, but no evidence for the BRAF V600E mutation was found (Figure 6). Similarly, low-level methylation was rare and confined to ITGA9 or PLCD1, and the BRAF mutation was absent among 13 age- and gender-matched cases whose colorectal cancers did a
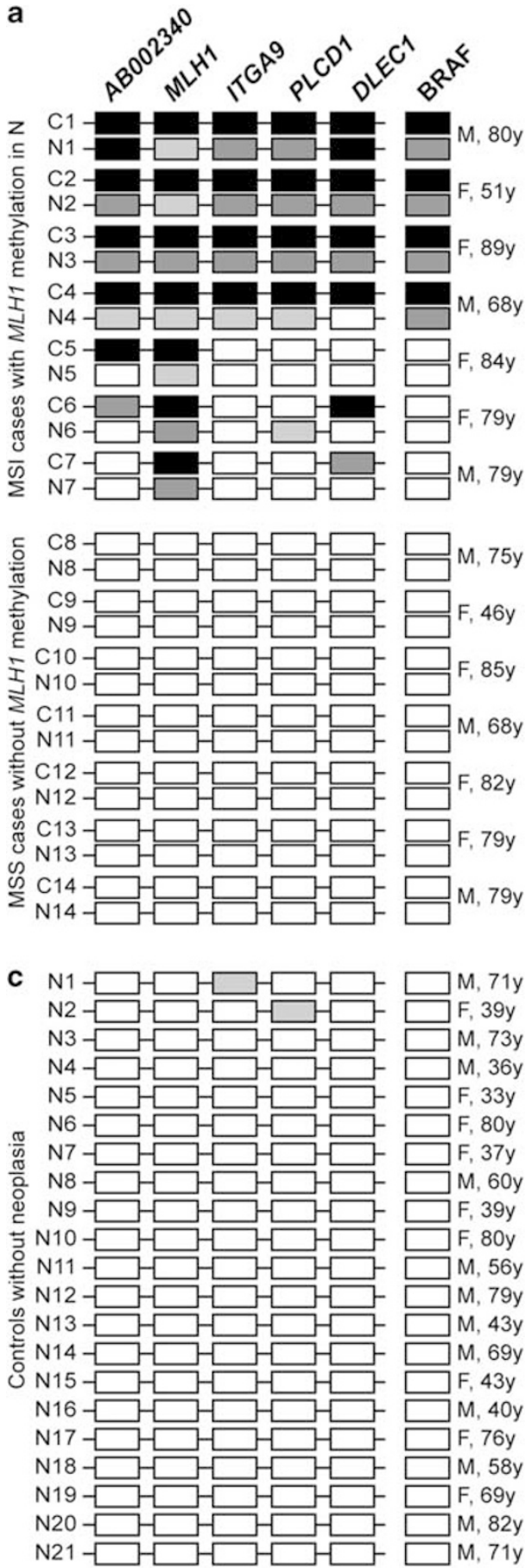

Methylation density:

PMR $>4$

Key: $\square$ PMR $>0.5-4$

$\square$ PMR 0.1-0.5

$\square$ PMR 0

BRAF: b
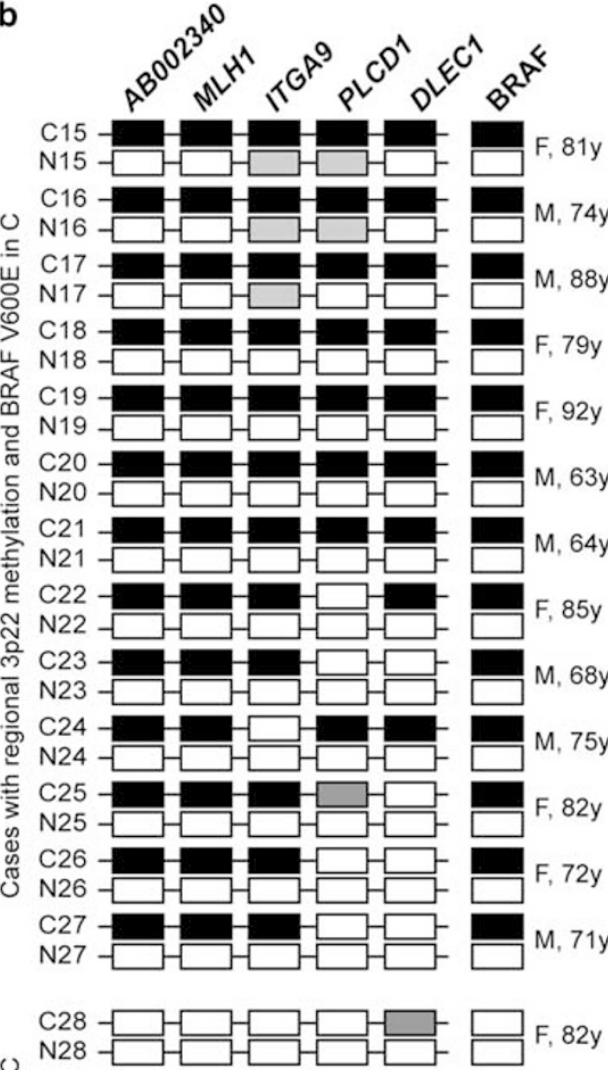

C $\mathrm{C} 29-\square \mathrm{M} 29 \mathrm{M}$

C30- $\square$ M, 90y

$\mathrm{N} 30-\square \mathrm{M}, 90$

I C31

C32 32 C

ᄃ $\mathrm{C} 33-\square-\square, \square, 58 \mathrm{y}$

N33- $\longrightarrow$

I C34-口

N $\mathrm{C} 35-\square$ F, 84y

ले N35- $\square-\square-\square$

든 $\mathrm{N} 36-\square$ M, 65y

\& C37 - $\square-\square$ M, 71y

N37-口 $\mathrm{N} 38$

N38 ${ }^{\mathrm{C}} 38$ F, 81y

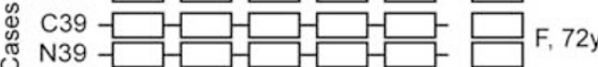

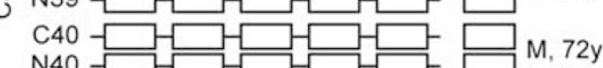

$\mathrm{N} 40$

V600E mutant, $\mathrm{dCt}<6.5$

$\square$ V600E mutant, dCt 6.5-10

$\square$ V600 wild-type, dCt $>11$ 

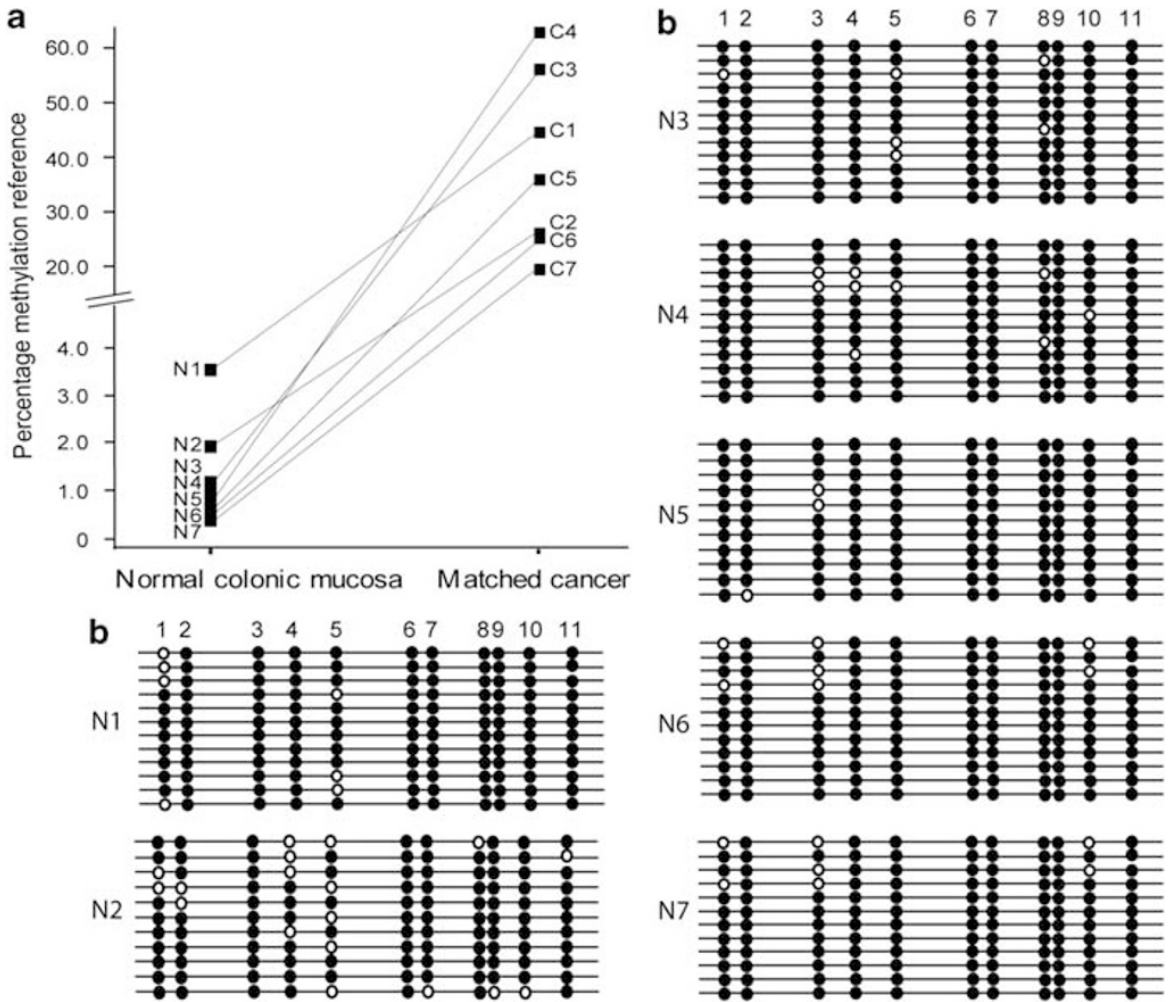

Figure 7 Presence of low-level MLH1 methylation in the normal colorectal mucosa of seven cases with correspondingly methylated colorectal cancers. (a) Paired dot-plot showing the relative levels of MLH1 methylation detected in pairs of normal colorectal mucosa (N) and carcinoma (C) of seven cases with microsatellite unstable colorectal cancers. Lines link the two specimens from each case. Individuals are numbered according to Table 6 and Figure 6. (b) Epigrams of clonally sequenced amplicons derived from real-time quantitative methylation-specific PCR products from the normal colorectal mucosa of the same seven cases. Each horizontal line corresponds to a single amplicon, and each circle represents a single CpG dinucleotide located between primer-binding sites. Black and white circles indicate methylated and unmethylated CpGs, respectively. Each of the seven products confirmed the presence of hypermethylated alleles in the normal colorectal mucosa, although some degree of mosaicism was observed, with a proportion of unmethylated CpGs, most notably in N2. This confirmed that although overall levels of allelic methylation in the normal colonic mucosa were low, the affected alleles were densely methylated.

not have regional 3p22 methylation and were BRAF wild type, as well as the 21 individuals without neoplasia (Figure 6). Thus, low levels of regional 3p22 methylation and BRAF V600E mutation appear to be infrequent in the normally appearing colonic mucosa, even when that mucosa is adjacent to a cancer showing high levels of these molecular features. These findings provided no evidence to suggest that either regional 3p22 methylation or BRAF mutation was precedent.

\section{Discussion}

This study of a large Australian cohort of sporadic colorectal cancers has confirmed that methylation of MLH1 occurs in a confined subset $(10.1 \%)$ of colorectal neoplasia and correlates closely with the clinicopathological characteristics typically associated with microsatellite unstable cancers, including older age, female gender, proximal location, lower tumour stage, mucinous histology and high grade, as well as the key molecular features of BRAF V600E mutation and CIMP.$+^{5,33,38-42}$ We found no evidence for an association between the $M L H 1$ promoter germline SNP c.-93G $>$ A genotype and an increased risk of MLH1 methylation or microsatellite instability in a case-control study of this cohort, arguing against a cis-acting role for this SNP in conferring susceptibility to methylation. In previous studies in which a positive association was found between the G>A genotype and microsatellite instability, either familial cases were retained in the cohort or the study group comprised early-onset cases, ${ }^{8-11}$ suggesting that the genotype may be linked to founder mutations that give rise to familial or early-onset cancer phenotypes in these populations. Although in one study of a large colorectal cancer cohort, the c.-93G $>$ A genotype was shown to be associated with MLH1 methylation, the BRAF V600E mutation as well as CIMP + among sporadic microsatellite unstable cancers, nevertheless a stronger association between the G>A genotype was demonstrated among the microsatellite unstable cases with a positive family history. ${ }^{10}$ In our study cohort, cases with a significant family history and known carriers of germline mutations that confer a hereditary colorectal cancer syndrome were 
Table 6 Clinicopathological details of individuals harbouring low levels of MLH1 methylation in their normal colonic mucosa

\begin{tabular}{lllllll}
\hline Case & Age & Sex & Tumour location & Microsatellite status & CIMP status & Associated polyps \\
\hline 1 & 51 & F & Right & MSI & CIMP+ & 3 HPs, 2 conventional and 1 serrated Ad \\
2 & 80 & F & Right & MSI & CIMP+ & Multiple HPs and conventional Ads \\
3 & 84 & F & Left & MSI & CIMP+ & 3 HPs, 2 serrated Ads \\
4 & 89 & F & Left & MSI & CIMP+ & 4 HPs \\
5 & 67 & M & Left & MSI & CIMP- & None \\
6 & 79 & M & Right & MSI & CIMP- & None \\
7 & 80 & M & Right & & None
\end{tabular}

M, male; F, female; MSI, microsatellite instability; HP, hyperplastic polyp.

Conventional adenomas (Ads) comprise tubular, tubulovillus and villus adenomas.

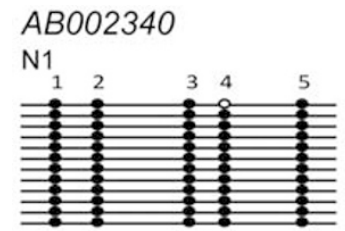

N3

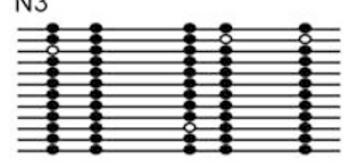

PLCD1

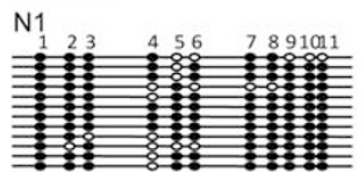

N3

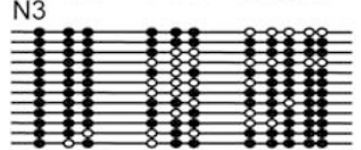

N2O

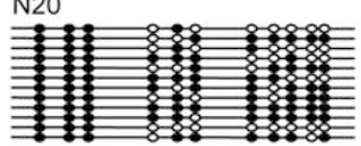

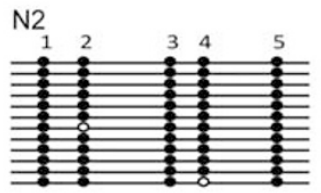
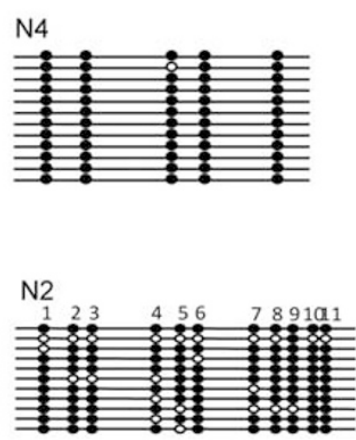

N4
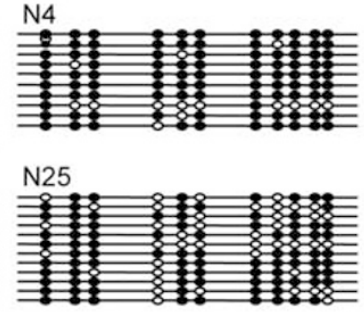

ITGA9

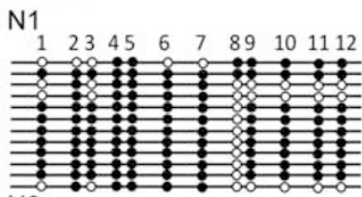

N3
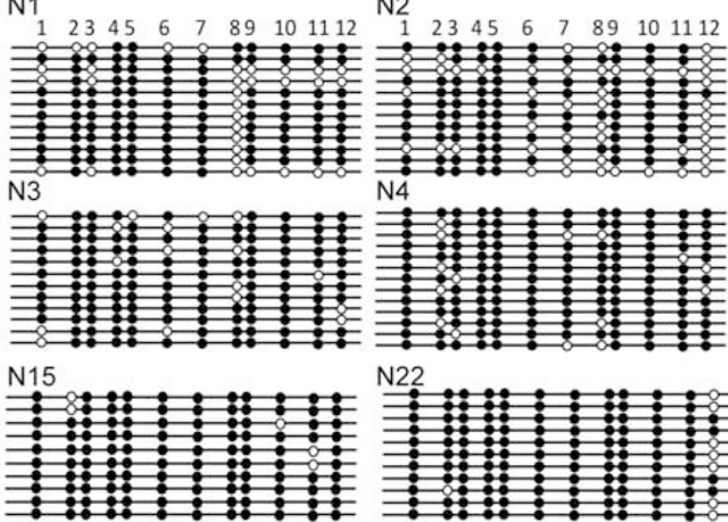
N4
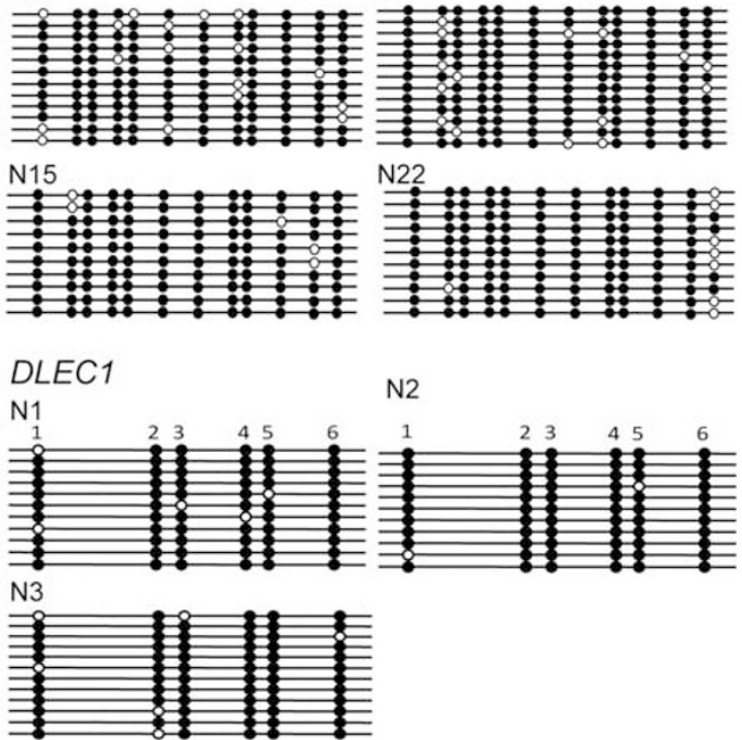

Figure 8 Presence of low-level methylation of 3p22 genes in the normal colorectal mucosa of cases with colorectal cancer. Epigrams of clonally sequenced amplicons from real-time methylation-specific PCR products of 3p22 genes, as labelled, are shown. Each horizontal line corresponds to a single amplicon, and each circle represents a single CpG dinucleotide located between primer-binding sites. Black and white circles indicate methylated and unmethylated CpGs, respectively. Normal colonic mucosa samples (N) are labelled according to Table 6 and Figure 6.

omitted, suggesting that the G>A SNP is not associated with an increased risk of MLH1 methylation or microsatellite instability among sporadic cases. Nevertheless, in sporadic endometrial and colorectal cancer populations in which an association with this SNP variant has been reported, these have been weak, with modest odds ratios. ${ }^{7}$ Thus, a minor elevation in the risk of MLH1 methylation or microsatellite instability observed in some cancer populations may not be replicated in others. This is in contrast to the c.-56C $>$ T SNP (rs16906252) of the DNA repair gene $M G M T$, which correlates strongly with the presence of MGMT promoter methylation in both colorectal carcinoma and non-neoplastic tissues, illustrating that cis-acting elements can have an instrumental role in gene methylation. ${ }^{43-45}$ The lack of any association between MLH1 methylation and the c.-93G > A genetic variant in our cohort is consistent with the finding, instead, of a strong correlation between methylation of $M L H 1$ and neighbouring genes within the contiguous $3 \mathrm{p} 22$ chromosomal region, arguing for a fundamental epigenetic basis to MLH1 inactivation in sporadic microsatellite unstable tumours.

We have extended our previous findings from a pilot study of colorectal cancers to this large cohort and confirmed that methylation of MLH1 and each of four nearby genes was strongly associated with 
methylation of each of the other genes within this region (Table 4). Furthermore, methylation of other 3p22 genes, AB002340, ITGA9, PLCD1 and DLEC1, individually or as a group of $\geq 3$ of 5 genes, also correlated with most clinicopathological and molecular features that were strongly associated with MLH1-methylated colorectal carcinoma (Table 2), reinforcing the notion that methylation of $3 \mathrm{p} 22$ genes occurs concomitantly with MLH1 in a considerable subset of sporadic microsatellite unstable colorectal cancers. This allowed the colorectal cancers in the cohort to be dichotomized into two groups; positive and negative for regional $3 \mathrm{p} 22$ methylation, defined as methylation of $3-5$ and 0-2 genes, respectively. This dichotomy is consistent with the criteria used by others for categorizing tumours, as exemplified by CIMP status, ${ }^{13,14}$ facilitating analyses between regional 3p22 methylation and other clinicopathological or molecular features that are reported in a categorical manner. However, the present study now shows that regional 3p22 methylation was more frequent in BRAF V600E mutant colorectal cancers regardless of microsatellite stability status, such that methylation of multiple 3 p22 genes is not restricted to microsatellite unstable cancers, as we previously reported. ${ }^{18} \mathrm{~A}$ small proportion of BRAF V600E mutant microsatellite stable cancers demonstrated concurrent methylation of 3p22 genes other than MLH1. Thus, it appears that methylation may spread stochastically across the 3 p22 chromosomal domain, only giving rise to the microsatellite instability phenotype when methylation encompasses MLH1.

The molecular mechanism by which methylation of genes within this cluster occurs remains unknown. We have previously shown that the LRRFIP and GOLGA2 promoters are not prone to methylation in colorectal cancer. ${ }^{18}$ Thus, a simplistic linear model fails to explain the close association between methylation of the 3p22 gene cluster, suggesting that a higher degree of complexity is involved in epigenetic silencing, perhaps involving the threedimensional structure of DNA. Nevertheless, longrange epigenetic silencing may provide some explanation for genes subject to methylation being refractory to reactivation by drugs that target repressive epigenetic modifications. It has previously been shown that the upregulation of $M L H 1$ achieved in colorectal carcinoma cell lines by treatment with methyltransferase and deacetylase inhibitors is transient, with a gradual reversal to the silenced state following drug withdrawal, ${ }^{46}$ possibly because of heterochromatinization on a regional basis.

A novel finding in this study was the close correlation between methylation of the 3p22 genes, both individually and as a cluster of $3-5$ together, and the CIMP + phenotype. Regional 3p22 methylation markers may thus serve as an alternative set of markers to characterize CIMP status, providing further support for the previous recommendation that MLH1 should be included as one of the markers in the panel for the characterization of CIMP $+{ }^{16}$ It was notable that CIMP + and the BRAF V600E mutation were all independent predictors of regional 3p22 methylation in multivariate analysis, despite their strong associations with one another. This suggests that heterogeneity in genetic and epigenetic events may still underlie the development of a given subset of colorectal cancers with strong molecular and clinicopathological similarity. The fact that mucinous histology was also a significant predictor of 3p22 methylation is not entirely surprising, given that BRAF V600E mutation, CIMP + and microsatellite instability were concordantly more frequent in mucinous colorectal cancers. ${ }^{40}$ Previous observations between the BRAF V600E mutation and methylation of multiple genes at distinct loci in conjunction with CIMP + have been reported. ${ }^{14,16,47-48}$ One other study has also reported the close association between long-range epigenetic silencing of the 2q14 region and CIMP + in sporadic colorectal cancer. ${ }^{24}$ Taken together, the independent findings of long-range epigenetic silencing of both the 3p22 and 2q14 regions in the context of CIMP + provide further support for a common mechanism governing epigenetic dysregulation that presents with the overlapping features of long-range epigenetic silencing and CIMP in the development of sporadic colorectal cancer. Our findings provide further evidence to suggest that these two epigenetic events are not independent, but represent a singular phenotype. The CIMP + phenotype may thus be more appropriately conceptualized as the presence of areas of long-range methylation affecting several chromosomal regions, rather than the simultaneous methylation of discrete loci. However, this remains to be tested definitively in regions surrounding current diagnostic markers of CIMP +.

Finally, we show that methylation of the critical Deng-C region of $M L H 1$ occurs infrequently in the apparently normal colonic mucosa of individuals with microsatellite unstable cancers, although at low levels. Furthermore, we show for the first time that methylation of flanking 3 p22 genes can also occur at low levels in the normal colorectal mucosa of colorectal cancer cases. We consider it unlikely that these findings occurred as a consequence of contamination of the normal tissue with tumour cells, given that the normal colorectal mucosa samples were taken as far as possible $(>10 \mathrm{~cm})$ from the cancer tissue and the 3p22 methylation profile in some normal colorectal mucosa samples were different from the paired carcinomas. Previous studies have similarly shown that a given gene methylated within the normal mucosa is usually methylated at lower levels than that seen in an adjacent cancer. ${ }^{17,49}$ Although these colorectal mucosa samples were macroscopically normal, it is conceivable that they contained aberrant cryptic foci. Indeed, the presence of the BRAF V600E 
mutation, ${ }^{50,51}$ as well as methylation of numerous genes including $M L H 1,{ }^{52-54}$ have previously been identified in these benign lesions. Nevertheless, the occurrence of these molecular event may represent a 'field defect' that underlies the development of metachronous colorectal neoplasia in some patients. ${ }^{55}$ Mechanistically, it has been suggested that the low level and mosaic patterns of methylation can provide a nidus of methylation, around which subsequent methylation can spread through stimulation of de novo methyltransferase activity. ${ }^{56}$ An interesting observation was that four individuals in whom concomitant 3p22 methylation occurred in conjunction with the BRAF V600E mutation in their apparently normal colonic mucosa had each developed hyperplastic polyps, and in some cases additional adenomas. Although these individuals did not present with an additional colorectal carcinoma, the finding of pre-neoplastic lesions is consistent with a common molecular mechanism underlying their phenotype. Unfortunately, no tissue was available from these polyps to determine if they demonstrated a similar molecular profile to support this notion. However, other groups have demonstrated extensive methylation of multiple genes in conjunction with the BRAF V600E mutation in the serrated polyps of colorectal cancer cases ${ }^{47,57}$ as well as in the normal colonic mucosa of individuals with hyperplastic polyposis or colorectal cancer, suggesting that in rare cases these molecular defects may serve as a field defect in colorectal neoplasia. ${ }^{57,58}$

In summary, our findings show that concomitant methylation of the 3 p22 region is a consistent finding in CIMP + colorectal cancers, and occurs predominantly, but not exclusively in microsatellite unstable tumours. Furthermore, we demonstrate that low-level methylation of $M L H 1$ and other 3 p22 genes, with the concurrent BRAF V600E mutation, can occur in the normal colonic mucosa of colorectal cancer cases, although rarely, and that this may predispose to the development of neoplasia of the serrated pathway, including hyperplastic polyps, serrated adenomas and sporadic microsatellite unstable/CIMP + colorectal carcinoma.

\section{Acknowledgements}

We thank Deborah Packham, Chau-To Kwok, Su Ku, Vita Ap Lin, Robert Rapkins and Luke Hesson for technical assistance. This research was supported by the Cancer Council NSW and the Cancer Institute NSW. JJW was the recipient of an Australian Endeavour International Postgraduate Research Scholarship (EIPRS).

\section{Disclosure/conflict of interest}

The authors declare no conflict of interest.

\section{References}

1 Wong JJ, Hawkins NJ, Ward RL. Colorectal cancer: a model for epigenetic tumorigenesis. Gut 2007;56: 140-148.

2 Ionov Y, Peinado MA, Malkhosyan S, et al. Ubiquitous somatic mutations in simple repeated sequences reveal a new mechanism for colonic carcinogenesis. Nature 1993;363:558-561.

3 Thibodeau SN, Bren G, Schaid D. Microsatellite instability in cancer of the proximal colon. Science 1993;260:816-819.

4 Kane MF, Loda M, Gaida GM, et al. Methylation of the hMLH1 promoter correlates with lack of expression of hMLH1 in sporadic colon tumors and mismatch repairdefective human tumor cell lines. Cancer Res 1997;57: 808-811.

5 Herman JG, Umar A, Polyak K, et al. Incidence and functional consequences of hMLH1 promoter hypermethylation in colorectal carcinoma. Proc Natl Acad Sci USA 1998;95:6870-6875.

6 Deng G, Bell I, Crawley S, et al. BRAF mutation is frequently present in sporadic colorectal cancer with methylated hMLH1, but not in hereditary nonpolyposis colorectal cancer. Clin Cancer Res 2004;10: 191-195.

7 Chen H, Taylor NP, Sotamaa KM, et al. Evidence for heritable predisposition to epigenetic silencing of MLH1. Int J Cancer 2007;120:1684-1688.

8 Raptis S, Mrkonjic M, Green RC, et al. MLH1 -93G > A promoter polymorphism and the risk of microsatelliteunstable colorectal cancer. J Natl Cancer Inst 2007;99: 463-474.

9 van Roon EH, van Puijenbroek M, Middeldorp A, et al. Early onset MSI-H colon cancer with MLH1 promoter methylation, is there a genetic predisposition? BMC Cancer 2010;10:180.

10 Samowitz WS, Curtin K, Wolff RK, et al. The MLH1 -93 $\mathrm{G}>\mathrm{A}$ promoter polymorphism and genetic and epigenetic alterations in colon cancer. Genes Chromosomes Cancer 2008;47:835-844.

11 Hubner RA, Houlston RS. Re: MLH1 93G > A promoter polymorphism and the risk of microsatellite-unstable colorectal cancer. J Natl Cancer Inst 2007;99:1490; author reply -1 .

12 Mei M, Deng D, Liu TH, et al. Clinical implications of microsatellite instability and MLH1 gene inactivation in sporadic insulinomas. J Clin Endocrinol Metab 2009;94:3448-3457.

13 Toyota M, Ahuja N, Ohe-Toyota M, et al. CpG island methylator phenotype in colorectal cancer. Proc Natl Acad Sci USA 1999;96:8681-8686.

14 Weisenberger DJ, Siegmund KD, Campan M, et al. CpG island methylator phenotype underlies sporadic microsatellite instability and is tightly associated with BRAF mutation in colorectal cancer. Nat Genet 2006;38:787-793.

15 Samowitz WS, Albertsen H, Herrick J, et al. Evaluation of a large, population-based sample supports a CpG island methylator phenotype in colon cancer. Gastroenterology 2005;129:837-845.

16 Ogino S, Kawasaki T, Kirkner GJ, et al. Evaluation of markers for CpG island methylator phenotype (CIMP) in colorectal cancer by a large population-based sample. J Mol Diagn 2007;9:305-314.

17 Frigola J, Song J, Stirzaker C, et al. Epigenetic remodeling in colorectal cancer results in coordinate 
gene suppression across an entire chromosome band. Nat Genet 2006;38:540-549.

18 Hitchins MP, Lin VA, Buckle A, et al. Epigenetic inactivation of a cluster of genes flanking MLH1 in microsatellite-unstable colorectal cancer. Cancer Res 2007;67:9107-9116.

19 Protopopov A, Kashuba V, Zabarovska VI, et al. An integrated physical and gene map of the $3.5-\mathrm{Mb}$ chromosome 3p21.3 (AP20) region implicated in major human epithelial malignancies. Cancer Res 2003;63: 404-412.

20 Senchenko V, Liu J, Braga E, et al. Deletion mapping using quantitative real-time PCR identifies two distinct 3 p21.3 regions affected in most cervical carcinomas. Oncogene 2003;22:2984-2992.

21 Senchenko VN, Liu J, Loginov W, et al. Discovery of frequent homozygous deletions in chromosome 3p21.3 LUCA and AP20 regions in renal, lung and breast carcinomas. Oncogene 2004;23:5719-5728.

22 Shu J, Jelinek J, Chang $\mathrm{H}$, et al. Silencing of bidirectional promoters by DNA methylation in tumorigenesis. Cancer Res 2006;66:5077-5084.

23 Seng TJ, Currey N, Cooper WA, et al. DLEC1 and MLH1 promoter methylation are associated with poor prognosis in non-small cell lung carcinoma. Br J Cancer 2008;99:375-382.

24 Karpinski P, Ramsey D, Grzebieniak Z, et al. The CpG island methylator phenotype correlates with longrange epigenetic silencing in colorectal cancer. Mol Cancer Res 2008;6:585-591.

25 Ogino S, Cantor M, Kawasaki T, et al. CpG island methylator phenotype (CIMP) of colorectal cancer is best characterised by quantitative DNA methylation analysis and prospective cohort studies. Gut 2006;55: 1000-1006.

26 Greene FL, Fritz AG, Balch CM, et al. (eds). AJCC Cancer Staging Handbook.. Springer-Verlag: New York, 2002.

27 Deng G, Chen A, Hong J, et al. Methylation of CpG in a small region of the hMLH1 promoter invariably correlates with the absence of gene expression. Cancer Res 1999;59:2029-2033.

28 Eads CA, Danenberg KD, Kawakami K, et al. MethyLight: a high-throughput assay to measure DNA methylation. Nucleic Acids Res 2000;28:E32.

29 Ogino S, Kawasaki T, Brahmandam M, et al. Precision and performance characteristics of bisulfite conversion and real-time PCR (MethyLight) for quantitative DNA methylation analysis. J Mol Diagn 2006;8:209-217.

30 Ward RL, Turner J, Williams R, et al. Routine testing for mismatch repair deficiency in sporadic colorectal cancer is justified. J Pathol 2005;207:377-384.

31 Packham D, Ward RL, Lin VA, et al., Implementation of novel pyrosequencing assays to screen for common mutations of BRAF and KRAS in a cohort of sporadic colorectal cancers. Diagn Mol Pathol 2009;18:62-71.

32 Jarry A, Masson D, Cassagnau E, et al. Real-time allelespecific amplification for sensitive detection of the BRAF mutation V600E. Mol Cell Probes 2004;18: 349-352.

33 Ward R, Meagher A, Tomlinson I, et al. Microsatellite instability and the clinicopathological features of sporadic colorectal cancer. Gut 2001;48:821-829.

34 Gazzoli I, Loda M, Garber J, et al., A hereditary nonpolyposis colorectal carcinoma case associated with hypermethylation of the MLH1 gene in normal tissue and loss of heterozygosity of the unmethylated allele in the resulting microsatellite instability-high tumor. Cancer Res 2002;62:3925-3928.

35 Suter CM, Martin DI, Ward RL. Germline epimutation of MLH1 in individuals with multiple cancers. Nat Genet 2004;36:497-501.

36 Hitchins $\mathrm{M}$, Williams $\mathrm{R}$, Cheong $\mathrm{K}$, et al. MLH1 germline epimutations as a factor in hereditary nonpolyposis colorectal cancer. Gastroenterology 2005; 129:1392-1399.

37 Hitchins MP, Wong JJ, Suthers G, et al. Inheritance of a cancer-associated MLH1 germ-line epimutation. N Engl J Med 2007;356:697-705.

38 Samowitz WS, Sweeney C, Herrick J, et al. Poor survival associated with the BRAF V600E mutation in microsatellite-stable colon cancers. Cancer Res 2005b;65:6063-6069.

39 Malesci A, Laghi L, Bianchi P, et al. Reduced likelihood of metastases in patients with microsatellite unstable colorectal cancer. Clin Cancer Res 2007;13: 3831-3839.

40 Tanaka H, Deng G, Matsuzaki K, et al. BRAF mutation, CpG island methylator phenotype and microsatellite instability occur more frequently and concordantly in mucinous than non-mucinous colorectal cancer. Int J Cancer 2006;118:2765-2771.

41 Wheeler JM, Loukola A, Aaltonen LA, et al. The role of hypermethylation of the hMLH1 promoter region in HNPCC versus MSI+ sporadic colorectal cancers. J Med Genet 2000;37:588-592.

42 Ward RL, Cheong K, Ku SL, et al. Adverse prognostic effect of methylation in colorectal cancer is reversed by microsatellite instability. J Clin Oncol 2003;21:3729-3736.

43 Ogino S, Hazra A, Tranah GJ, et al. MGMT germline polymorphism is associated with somatic MGMT promoter methylation and gene silencing in colorectal cancer. Carcinogenesis 2007;28:1985-1990.

44 Hawkins NJ, Lee JH, Wong JJ, et al. MGMT methylation is associated primarily with the germline $\mathrm{C}>\mathrm{T}$ SNP (rs16906252) in colorectal cancer and normal colonic mucosa. Mod Pathol 2009;22:1588-1599.

45 Candiloro IL, Dobrovic A. Detection of MGMT promoter methylation in normal individuals is strongly associated with the $\mathrm{T}$ allele of the rs16906252 MGMT promoter single nucleotide polymorphism. Cancer Prev Res (Phila Pa) 2009;2:862-867.

46 McGarvey KM, Fahrner JA, Greene E, et al. Silenced tumor suppressor genes reactivated by DNA demethylation do not return to a fully euchromatic chromatin state. Cancer Res 2006;66:3541-3549.

47 Kambara T, Simms LA, Whitehall VLJ, et al. BRAF mutation is associated with DNA methylation in serrated polyps and cancers of the colorectum. Gut 2004b;53:1137-1144.

48 Samowitz WS, Albertsen H, Herrick J, et al. Evaluation of a large, population-based sample supports a CpG island methylator phenotype in colon cancer. Gastroenterology 2005a;129:837-845.

49 Shen L, Kondo Y, Rosner GL, et al. MGMT promoter methylation and field defect in sporadic colorectal cancer. J Natl Cancer Inst 2005;97:1330-1338.

50 Beach R, Chan AO, Wu TT, et al. BRAF mutations in aberrant crypt foci and hyperplastic polyposis. Am J Pathol 2005;166:1069-1075.

51 Rosenberg DW, Yang S, Pleau DC, et al. Mutations in BRAF and KRAS differentially distinguish serrated versus non-serrated hyperplastic aberrant crypt foci in humans. Cancer Res 2007;67:3551-3554. 
52 Chan AO, Broaddus RR, Houlihan PS, et al. CpG island methylation in aberrant crypt foci of the colorectum. Am J Pathol 2002;160:1823-1830.

53 Luo L, Chen WD, Pretlow TP. CpG island methylation in aberrant crypt foci and cancers from the same patients. Int J Cancer 2005;115:747-751.

54 Greenspan EJ, Jablonski MA, Rajan TV, et al. Epigenetic alterations in RASSF1A in human aberrant crypt foci. Carcinogenesis 2006;27:1316-1322.

55 Slaughter DP, Southwick HW, Smejkal W. Field cancerization in oral stratified squamous epithelium; clinical implications of multicentric origin. Cancer 1953;6:963-968.
56 Lorincz MC, Schubeler D, Hutchinson SR, et al. DNA methylation density influences the stability of an epigenetic imprint and Dnmt3a/b-independent de novo methylation. Mol Cell Biol 2002;22: 7572-7580.

57 Minoo P, Baker K, Goswami R, et al. Extensive DNA methylation in normal colorectal mucosa in hyperplastic polyposis. Gut 2006;55:1467-1474.

58 Kadiyska TK, Konstantinova DV, Atanasov VR, et al. Frequency and application of the hot spot BRAF gene mutation (p.V600E) in the diagnostic strategy for hereditary nonpolyposis colorectal cancer. Cancer Detect Prev 2007;31:254-256.

Supplementary Information accompanies the paper on Modern Pathology website (http://www.nature.com/ modpathol) 